\title{
KONSTITUSIONALITAS TANGGUNG JAWAB NEGARA DALAM MELINDUNGI PEMBELA HAK ASASI MANUSIA
}

\author{
Adi Purnomo Santoso ${ }^{*}$, Dina Liliyana ${ }^{1}$ \\ ${ }^{1}$ Fakultas Hukum,Universitas Nasional \\ Email: adipurnomosantoso80@gmail.com,dinaliliyana.unas@gmail.com \\ *Korespondensi penulis: adipurnomosantoso80@gmail.com \\ (Submission 31-03-2021, Revission 22-04-2021, Accepted 04-06-2021)
}

\begin{abstract}
After the amendment of 1999-2002, the Constitution of the Republic of Indonesia 1945 (UUD NRI 1945) as the constitution has contained material or substance more complete to the protection of human rights (human rights) than before the amendment. This is however a commitment of the state to qualify the existence of Indonesia as a state of Pancasila law that embraces constitutional democracy. In the epicentre of human rights protection, including how the state's responsibility in protecting human rights defenders. However, in contrast to what is regulated in the text of the constitution, in practice as revealed in the report of the Institute for Public Studies and Advocacy (ELSAM) noted that during 2019, there have been 27 cases of violence against environmental defenders with the spread of cases reaching 14 provinces and 24 districts and resulted in 127 individuals and 50 groups of Environmental Human Rights Defenders being victimized. This study aims to describe and review how the responsibility of the state in protecting human rights defenders constitutionally. The research method used is normative research with qualitative analysis approach, where data collection is done through literature studies. The result of this research is that Indonesia as the state of Pancasila law has constitutionally mandated the state (government) to specifically protect human rights defenders. By protecting human rights defenders, the state is not only implementing the constitution as the substance of living law, but also as an effort to promote universal human dignity and dignity.
\end{abstract}

Keywords: constitution, state law, human rights, human rights defenders, and state responsibilities.

\begin{abstract}
Abstrak
Pasca amandemen tahun 1999-2002, Undang-Undang Dasar Negara Republik Indonesia 1945 (UUD NRI 1945) selaku konstitusi telah memuat materi atau substansi yang lebih lengkap terhadap perlindungan hak asasi manusia (HAM) dibandingkan sebelum amandemen. Hal ini bagaimanapun merupakan komitmen negara untuk memenuhi syarat keberadaan Indonesia sebagai negara hukum Pancasila yang menganut demokrasi konstitusional. Dalam episentrum perlindungan terhadap HAM, termasuk pula di dalamnya bagaimana tanggung jawab negara dalam melindungi para pembela HAM. Namun, berbanding terbalik dengan apa yang diatur dalam teks konstitusi, dalam praktiknya sebagaimana diungkap dalam laporan Lembaga Studi dan Advokasi Masyarakat (ELSAM) mencatat bahwa selama 2019, telah terjadi 27 kasus kekerasan Pembela HAM atas
\end{abstract}


lingkungan dengan persebaran kasus mencapai 14 Provinsi dan 24 kabupaten dan mengakibatkan 127 individu dan 50 kelompok pembela HAM atas lingkungan menjadi korban. Penelitian ini bertujuan untuk mendeskripsikan dan mengkaji bagaimana tanggung jawab negara dalam melindungi pembela HAM secara konstitusional. Metode penelitian yang digunakan adalah penelitian normatif dengan pendekatan analisis kualitatif, di mana pengumpulan data yang dilakukan melalui studi kepustakaan. Hasil dari penelitian ini ialah Indonesia selaku negara hukum Pancasila secara konstitusional telah mengamanahkan negara (pemerintah) untuk secara khusus melindungi para pembela HAM. Dengan melindungi para pembela HAM, negara bukan hanya mengimplementasikan konstitusi sebagai substansi hukum yang hidup (the living of law), melainkan pula sebagai upaya mengedepankan harkat dan martabat manusia secara universal.

Kata kunci: konstitusi, negara hukum, HAM, pembela HAM, dan tanggung jawab negara.

\section{PENDAHULUAN \\ Latar Belakang}

Pasca amandemen Undang-Undang Dasar Negara Republik Indonesia 1945 (UUD NRI 1945) pada tahun 1999-2002, Indonesia makin memantapkan diri sebagai negara demokrasi konstitusional yang mengakui dan menghormati Hak Asasi Manusia (HAM). Hal itu selain dinyatakan di dalam Pasal 1 ayat (3) yang eksplisit memuat bahwa Indonesia adalah negara hukum, lalu dilengkapi dengan pernyataan bahwa kedaulatannya berada di tangan rakyat dan dilaksanakan menurut Undang-Undang Dasar sebagaimana dalam Pasal 1 ayat (2). Lebih lanjut, penegasan Indonesia sebagai negara demokrasi konstitusional itu kemudian diiringi dengan pengaturan tentang hak asasi manusia yang lebih luas dan komprehensif pada Bab khusus, yaitu Bab XI A UUD NRI 1945 yang terdiri dari Pasal 28A-28J. Dalam bab ini, semua aspek hak asasi mendapatkan jaminan. Aspek tersebut tidak hanya hak di bidang sipil dan politik, tetapi juga hak atas kesejahteraan masyarakat seperti hak di bidang ekonomi, sosial dan budaya. Jelaslah bahwa pengaturan HAM dalam UUD NRI 1945 merupakan komitmen negara untuk memenuhi syarat keberadaan Indonesia sebagai negara yang menganut demokrasi konstitusional (Saldi Isra, 2014).

Ketika diakui dan dilindungi secara konstitusional, bukan berarti dalam praktiknya penghormatan terhadap HAM secara pasti terjamin. Keberadaan dan pengakuan di tingkat konstitusi tentunya baru sebatas norma yang mengatur bahwa hak asasi manusia itu ada, diakui dan dilindungi. Di sisi lain, ihwal implementasinya bergantung pada ketersediaan infrastruktur kelembagaan, mekanisme dan komitmen penyelenggara negara.

Seiring dengan itu, dalam Siaran Pers yang dilakukan oleh Lembaga Studi dan Advokasi Masyarakat (ELSAM) bertajuk "Laporan Situasi Pembela HAM atas Lingkungan Tahun 2019", dijelaskan bahwa tahun 2019 merupakan tahun yang berat bagi masyarakat sipil yang sedang berjuang untuk kelestarian dan kedaulatan lingkungan dan Hak Asasi Manusia (HAM). Dalam laporan tersebut ELSAM mencatat bahwa selama 2019, telah terjadi 27 kasus kekerasan Pembela HAM atas Lingkungan dengan persebaran kasus mencapai 14 Provinsi dan 24 kabupaten. 
Kasus-kasus ini melibatkan delapan jenis kekerasan, yakni pembunuhan, penangkapan, penahanan, serangan fisik, perusakan, perampasan tanah, dan intimidasi, dan mengakibatkan 127 individu dan 50 kelompok Pembela HAM atas Lingkungan menjadi korban. Di antara keseluruhan kasus tersebut, kasus pembunuhan aktifis Golfrid Siregar dan percobaan pembunuhan keluarga Murdani, Direktur WALHI NTB menjadi kasus yang dianggap paling keras dan brutal (elsam.or.id, 23/04/2020).

Padahal, keberadaan aktivitas pembela HAM merupakan episentrum penegakan hukum yang seharusnya menjadi objek keseriusan negara. Hasrat predatoris rezim oligarki yang masih mengungkung negeri ini boleh jadi merasa gerah dan bahkan marah karena keserakahannya di sektor agraria dan lingkungan, diganggu oleh aktivitas para pembela HAM. Celakanya, alih-alih hadir guna mewujudkan amanat konstitusi, negara dalam hal ini pemerintah, tak mampu berbuat banyak. Hal ini setidaknya tercermin misalnya, dari kasus pembunuhan Golfrid Siregar yang justru dinyatakan sebagai kecelakaan tunggal lalu lintas oleh Polda Sumatera Utara.

Adapun rumusan yang akan diuraikan dalam penelitian ini adalah konsepsi pengakuan HAM dalam negara hukum Pancasila dan eksistensi Pembela HAM dalam hukum nasional maupun hukum internasional serta konstitusionalitas tanggung jawab negara dalam melindungi Pembela HAM.

\section{METODE PENELITIAN}

Penelitian ini menggunakan metode penelitian normatif dengan pendekatan analisis kualitatif. Penelitian ini dapat juga disebut atau diistilahkan dengan penelitian doktrinal yang menitikberatkan pada analisis kualitatif. Norma dalam hal ini mengenai asas-asas, norma, kaidah dari peraturan perundangan, putusan pengadilan, perjanjian serta doktrin (Mukti Fajar dan Yulianto Achmad, 2010).

Proses untuk menemukan aturan hukum, prinsip-prinsip hukum, maupun doktrin-doktrin hukum guna menjawab isu hukum yang dihadapi inilah yang dinamakan dengan penelitian hukum. Hal ini sesuai dengan karakter preskriptif ilmu hukum, dimana penelitian hukum dilakukan untuk menghasilkan argumentasi, teori atau konsep baru sebagai preskripsi dalam menyelesaikan masalah yang dihadapi. Dengan kata lain, penelitian hukum dilakukan untuk memecahkan isu hukum yang diajukan.

Dikatakan normatif, karena hukum itu diasumsikan sebagai sesuatu yang otonom sehingga keberlakuannya ditentukan oleh hukum itu sendiri bukan oleh faktor-faktor di luar hukum. Berdasarkan asumsi ini, hukum itu telah dianggap sempurna dan final sehingga tinggal dilaksanakan. Hukum adalah pedoman tingkah laku yang tidak boleh disimpangi karena ia merupakan perintah dari yang berdaulat, maka apabila tidak dilaksanakan akan mendapatkan sanksi (Zulfadli Barus, 2013).

Pelacakan sumber-sumber data yang digunakan terdiri atas sumber-sumber primer dan sumber-sumber sekunder. Sumber primer terdiri dari peraturan perundang-undangan, yaitu misalnya Undang-Undang Dasar Negara Republik Indonesia 1945, Undang-Undang Nomor 39 tahun 1999 tentang HAM, UndangUndang Nomor 26 tahun 2000 tentang Pengadilan HAM, dan Undang-Undang 
Nomor 13 tahun 2006 tentang Perlindungan Saksi dan Korban dan peraturan perundang-undangan lainnya. Selain itu juga meliputi produk-produk hukum internasional yang berkaitan dengan HAM diantaranya: Universal Declaration of Human Rights tahun 1948, International Covenant on Civil on Political Rights tahun 1966 (ICCPR), International Covenant on Economic, Social and Cultural Rights (ICESCR) tahun 1966, Convention on the Elimination of All Forms of Racial Discrimination (CERD) tahun 1966, Declaration on the Right and Responsibility of Individuals, Groups and Organs of Society to Promote and Protect Universally Recognized Human Rights and Fundamental Freedoms (Resolusi Majelis Umum PBS Nomor : 53/144 tanggal 9 Desember 1998). Sedangkan sumber-sumber sekunder terdiri dari buku, literatur, jurnal, dan berbagai artikel yang berkaitan dengan penelitian ini. Hasil penelitian yang diperoleh melalui studi kepustakaan ini akan dianalisis secara deskriptif kualitatif.

Selain menggunakan metode penelitian hukum, strategi yang digunakan dalam penemuan hukum penelitian ini adalah interpretasi hukum. Dalam model penelitian hukum ini terdapat konsep-konsep: konsistensi, deduktif, analisis, apriori, konkritisasi, interpretasi dan data kualitatif melalui library research (Zulfadli Barus, 2013).

\section{PEMBAHASAN}

\section{Negara Hukum Pancasila dan Hak Asasi Manusia}

Negara hukum Pancasila merupakan konsep negara hukum yang diterapkan di Indonesia berdasarkan nilai-nilai yang terkandung dalam Pancasila sebagai dasar negara. Oleh sebab itu, kedudukan Pembukaan UUD NRI 1945 yang juga memuat rumusan Pancasila, menjadi sumber hukum tertinggi bagi negara hukum Indonesia. Sebagaimana dijelaskan Mohammad Fajrul Falaakh, bahwa Pancasila dan UUD NRI 1945 harus dipahami sebagai suatu kesatuan utuh. Menurutnya, meminjam dalam penjelasan UUD NRI 1945 yang tidak lagi disebut sebagai bagian UUD NRI 1945, Pembukaan UUD NRI 1945 yang memuat rumusan Pancasila mengandung pokokpokok pikiran yang diwujudkan dalam pasal-pasalnya atau "Undang-Undang Dasar menciptakan pokok-pokok pikiran yang terkandung dalam 'pembukaan' dalam pasalpasalnya" (Mohammad Fajrul Falaakh, 2011).

Sebagaimana diketahui, di dalam sila kedua Pancasila, telah dinyatakan: "Kemanusiaan yang adil dan beradab". Bahkan dalam pembukaan UUD NRI 1945, tepatnya pada alinea pertama dinyatakan pula: "Bahwa sesungguhnya Kemerdekaan itu ialah hak segala bangsa dan oleh sebab itu, maka penjajahan di atas dunia harus dihapuskan, karena tidak sesuai dengan peri-kemanusiaan dan perikeadilan". Dengan kata lain, baik Pancasila maupun Pembukaan UUD NRI 1945, HAM diakui sebagai nilai-nilai yang harus dihormati, dilindungi dan dijamin. Tidak heran jika Wiratraman Herlambang menegaskan bahwa sebelum Deklarasi Universal HAM (Universal Declaration of Human Right) lahir, UUD NRI 1945 justru lebih dulu telah memiliki perspektif HAM yang progresif (Wiratraman P. Herlambang, 2007).

Lebih jauh, menurut Arief Hidayat, terdapat 5 (lima) karakteristik yang membedakan Negara hukum Pancasila dibandingkan konsep Negara hukum yang 
lain, salah satunya ia menguraikan bahwa: "Indonesia merupakan suatu negara kekeluargaan. Dalam suatu negara kekeluargaan terdapat pengakuan terhadap hak-hak individu (termasuk pula hak milik) atau HAM. Namun dengan tetap mengutamakan kepentingan nasional (kepentingan bersama) di atas kepentingan individu. Di satu sisi, ini sejalan dengan nilai sosial masyarakat Indonesia yang bersifat paguyuban, namun disisi lain juga sejalan pergeseran masyarakat Indonesia ke arah masyarakat modern yang bersifat patembayan. Konsepsi ini sangat berbeda dengan konsep negara hukum Barat yang menekankan pada kebebasan individu seluas-luasnya, sekaligus bertolak belakang dengan konsep negara hukum sosialisme-komunisme yang menekankan pada kepentingan komunal atau bersama. Dalam negara hukum Pancasila, diusahakan terciptanya suatu harmoni dan keseimbangan antara kepentingan individu dan kepentingan nasional (masyarakat) dengan memberikan pada negara kemungkinan untuk melakukan campur tangan sepanjang diperlukan bagi terciptanya tata kehidupan berbangsa dan bernegara yang sesuai dengan prinsip-prinsip Pancasila" (Indra Rahmatullah, 2020).

Guna mendukung hal itu, menurut Muladi, sebagai konsekuensi dianutnya negara hukum Pancasila, maka Pancasila ditempatkan sebagai margin of appreciation, artinya ditempatkan sebagai penyeimbang dan penyelaras bahkan pembenaran berlakunya nilai-nilai nasional dalam kerangka nilai-nilai universal. Sebagai margin of appreciation, maka Pancasila akan memiliki fungsi sebagai berikut (Muladi, 1997) :

1. Garis dimana pengawasan akan memberikan arah jalan pada kebijakan negara dalam membuat dan menyelenggarakan undang-undang.

2. Menemukan keseimbangan antara hak yang dijamin dan batasan yang diijinkan.

3. Menggerakkan prinsip justifikasi daripada interpretasi

4. Mencegah restriksi pelarangan yang tidak perlu.

5. Menghindari perselisihan yang merusak.

6. Standar proteksi yang seragam.

7. Dan memberikan fleksibilitas yang dibutuhkan untuk menghindari konfrontasi yang merusak.

Dengan kata lain, penghormatan, perlindungan dan jaminan terhadap HAM merupakan salah satu karakteristik dari Negara hukum Pancasila. Selain itu, harus diakui bahwa dari rumusan batang tubuh konstitusi dalam perubahan UUD NRI 1945 periode 1999-2002 adalah lebih baik dibandingkan dengan konstitusi sebelumnya dalam membangun sistem ketatanegaraan, salah satu utamanya terkait dengan meluasnya pengaturan jaminan terhadap HAM. Dari kualitas jaminan hakhaknya, UUD NRI 1945 pasca reformasi telah mengatur jauh lebih lengkap dibandingkan sebelum amandemen, dari 5 pasal (hak atas pekerjaan dan penghidupan yang layak bagi kemanusiaan, kemerdekaan berserikat dan berkumpul serta mengeluarkan pikiran dengan lisan dan tulisan, jaminan kemerdekaan beragama dan berkepercayaan, serta hak atas pengajaran, hak atas akses sumberdaya alam) menjadi setidaknya 17 pasal (dengan 38 substansi hak-hak yang beragam) yang terkait dengan hak asasi manusia (Wiratraman P. Herlambang, 2007). Pendapat 
lain, misalnya menurut Jimly Asshiddiqie (2006), bahkan menyebut bahwa UUD NRI 1945 pasca perubahan tahun 1999-2002 memuat sebanyak 27 substansi atau materi terkait HAM.

Meluasnya jaminan atas HAM melalui pasal-pasal di dalam UUD NRI 1945 itu sejatinya merupakan langkah maju dalam membangun pondasi hukum bernegara guna memperkuat kontrak penguasa-rakyat dalam semangat konstitusionalisme Indonesia. Semangat konstitusionalisme Indonesia harus mengedepankan 2 (dua) arah bangunan politik hukum konstitusinya, yakni: 1) pembatasan kekuasaaan agar tidak menggampangkan kesewenang-wenangan; dan 2) jaminan penghormatan, perlindungan dan pemenuhan HAM. Apalagi, kemajuan pasal-pasal HAM dalam UUD NRI 1945 selaku konstitusi merupakan kecenderungan global di berbagai negara tentang diakuinya prinsip universalisme HAM dan diyakini secara bertahap akan memperkuat kapasitas Negara dalam mendorong peradaban martabat kemanusiaan (Wiratraman P. Herlambang, 2007).

\section{Eksistensi Pembela HAM}

Pada kenyataannya, negara acapkali tidak dapat sepenuhnya melaksanakan kewajiban menghormati, melindungi dan menjamin HAM, sehingga menggugah banyak pihak, baik secara individu maupun berkelompok, untuk melakukan upayaupaya tertentu guna meningkatkan perlindungan dan pemajuan HAM. Biasanya mereka dikenal sebagai aktivis HAM atau pembela HAM atau Human Rights Defender (HRD). 1stilah HRD (Human Rights Defender) atau 'Pembela HAM' sendiri digunakan setelah adanya "Declaration on the Right and Responsibility of Individuals, Groups, and Organs of Society to Promote and Protect Universally Recognized Human Rights and Fundamental Freedom" yang kemudian diistilahkan dengan 'Deklarasi Pembela HAM' pada tahun 1998, di mana sebelumnya lebih banyak digunakan istiah-istllah seperti 'aktivis HAM', 'pekerja HAM'. 'pemantau HAM' (Rahayu, 2010).

Begitu pentingnya peran pembela HAM sehingga dinilai banyak kalangan menjadi aktor penting dalam berbagai upaya untuk melaksanakan kerangka kerja HAM secara intemasional. lstilah pembela HAM digunakan setelah adanya "Declaration on the Right and Responsibility of Individuals, Groups, and Organs of Society to Promote and Protect Universally Recognized Human Rights and Fundamental Freedom" (Deklarasi Pembela HAM) dalam Resolusi Majelis Umum PBB Nomor53/144 tahun 1998. Pasal 1 'Deklarasi Pembela HAM' ini menyatakan :"Everyone has the right, individually and in association with others, to promote and to strive for the protection and realization of human rights and fundamental freedom at the national and International levels." Berdasarkan definisi yang sangat luas tersebut maka banyak orang yang dapat dikategorikan sebagai pembela HAM, mulai dari aktivis organisasi internasional hingga individu yang bekerja dalam komunitasnya, terdiri dari berbagai macam profesi (Rahayu, 2009).

Pembela HAM (Human Rights Defender) merupakan bagian dari masyarakat yang mendorong negara untuk memenuhi kewajiban internasionalnya menghormati dan menjamin penghormatan HAM. Sekalipun demikian, sampai saat ini belum terdapat ketentuan yang secara khusus mengatur dan dapat menjadi 
landasan bagi perlindungan terhadap pembela HAM. Beberapa peraturan hukum nasional yang dimaksud, yang dapat dijadikan landasan hak dan tanggung jawab individu maupun kelompok untuk melakukan upaya perlindungan dan pemajuan HAM, diantaranya adalah Undang-Undang Nomor 39 tahun 1999 tentang HAM (Pasal 100-103), Undang-Undang Nomor 26 tahun 2000 tentang Pengadilan HAM (Pasal 34), dan Undang-Undang Nomor 13 tahun 2006 tentang Perlindungan Saksi dan Korban.

Di dalam peraturan-peraturan di atas, tidak satu pun pasal-pasalnya yang menyebutkan secara definitif dan mendetail mencantumkan hak-hak yang dimiliki oleh pembela HAM. Selain itu, di dalamnya juga tidak secara tegas memberikan perlindungan bagi aktivitas yang dilakukan oleh Pembela HAM sebagaimana diatur dalam 'Deklarasi Pembela HAM', sehingga masih memberikan ruang terjadinya pelanggaran terhadap pembela HAM.

Dalam kaitannya dengan aktivitas yang dilakukan oleh pembela HAM, tidak mengherankan jika Rahayu (2010) menjelaskan bahwa para pembela HAM sangat rentan mengalami pelanggaran HAM, baik berupa hambatan, kekerasan dan ancaman. Kekerasan yang dimaksud terdiri dalam berbagai bentuk, mulai dari hambatan prosedural, ancaman ringan hingga tindakan nyata yang mengakibatkan kematian. Adapun pelaku kekerasan terhadap pembela HAM di Indonesia dilakukan tidak hanya oleh aktor negara tapi juga non-negara, individu dan kelompok. Publik tentu masih mengingat nama-nama seperti Marsinah (aktivis buruh) yang dibunuh karena memperjuangkan hak - haknya sebagai buruh, Udin (wartawan Bernas) yang dibunuh setelah menulis kasus korupsi Bupati Bantul, atau Munir (aktivis HAM) yang diracun di pesawat dalam perjalanan menuju Belanda pada 6 September 2004 adalah sedikit contoh akan risiko yang harus dihadapi oleh para pembela HAM di Indonesia.

Menurut Hina Jilani (Special Representative of the Secretary General on Human Rights Defender tahun 2000 - Maret 2008) sebagaimana dikutip Rahayu (2010) mengemukakan bahwa para pembela HAM ini biasanya memiliki aktivitas utama yang bercirikan pada 9 (sembilan) hal berikut, yaitu:

1. All human rights for all (HAM untuk semua).

2. Human rights everywhere (HAM dimana-mana).

3. Local, national, regional and international action, artinya para pembela HAM dapat bekerja pada level lokal dan nasional, maupun intemasional.

4. Collecting and disseminating information on violations (melakukan investigasi dan mengumpulkan informasi tentang pelanggaranHAM).

5. Supporting victims of human rights violations (membantu korban pelanggaran HAM).

6. Action to secure accountability and to end impunity (menuntut pertanggungjawaban dan mengakhiri impunitas).

7. Supporting better governance and government policy (mendorong kebijakan pemerintahan yang lebih baik).

8. Contributing to the implementation of human rights treaties (kontribusi terhadap implementasi perjanjian HAM).

9. Human rights education and training (pendidikan dan pelatihan HAM). 
Oleh karena itu, dalam instrumen hukum internasional, diketahui memuat ketentuan yang mengukuhkan sentralnya pembela HAM dalam penegakan HAM. Diantaranya diatur di dalam (Rahayu, 2010) :

1. Universal Declaration of Human Rights 1948 (Pasal 19 dan 20).

2. International Covenant on Civil on Political Rights tahun 1966 (ICCPR) Pasal 21 dan Pasal 22 ayat (1).

3. International Covenant on Economic, Social and Cultural Rights (ICESCR) tahun 1966 Pasal 8.

4. Convention on the Elimination of All Forms of Racial Discrimination (CERD) tahun 1966 Pasal 5 (d) (viii) dan (ix).

5. Declaration on the Right and Responsibility of Individuals, Groups and Organs of Society to Promote and Protect Universally Recognized Human Rights and Fundamental Freedoms (Resolusi Majelis Umum PBS Nomor : 53/144 tanggal 9 Desember 1998).

\section{Konstitusionalitas Tanggung Jawab Negara dalam Penegakan HAM}

Konstitusi, bagaimanapun sebagaimana banyak ditafsirkan melalui materialisasi teks-teks telah memperlihatkannya sebagai konfigurasi politik yang bekerja. Artinya, konstitusi merupakan persepakatan secara sadar oleh para pembuat maupun pengambil kebijakan dengan sejumlah pemahaman dan kepentingan yang mereka miliki. Oleh sebab itu, UUD NRI 1945 meski dipercaya dalam idenya memiliki nilai-nilai dan makna yang maha penting dalam menata kehidupan ketatanegaraan, baik sosial, ekonomi dan politik, namun ia tetaplah sebagai hasil dari pergesekan dan tarik-menarik representasi politik-ekonomi dominan yang memiliki kekuasaan tertentu dalam mempengaruhinya. Itupun belumlah menjamin konsistensi berlakunya dalam kebijakan-kebijakan negara (Wiratraman P. Herlambang, 2007).

Dengan perspektif demikian, maka kita bisa mengatakan bahwa implementasi dari sebuah konstitusi yang baik belum tentu sejalan dengan apa yang terjadi di lapangan, utamanya menyangkut kebijakan-kebijakan suatu negara. Sebagai contoh di Thailand misalnya, The People's Constitution sebagaimana pernah dinukilkan oleh Lubis (2002) sebagai konstitusi yang nyaris sempurna, namun nyatanya pada masa rezim politik Thaksin Sinawatra berkuasa, kekuasaan bisa dengan gampang mempermainkannya. Terlebih ketika krisis politik melanda Kerajaan Thailand, militer atas restu Raja Bhumibol Adulyadej dapat pula menggulingkan Perdana Menteri dan mengganti konstitusi dengan konstitusi ala militer. Di Indonesia sendiri yakni di masa Soeharto berkuasa, juga menunjukkan hal yang serupa di mana konstitusi bisa dinegasikan oleh penguasa.

Berbagai macam hak dan kewajiban sebagai manifestasi prinsip-prinsip hak asasi manusia (HAM) yang dirumuskan dalam berbagai instrumen hukum (internasional) menempatkan HAM sebagai sekumpulan hak yang bersifat normatif yang harus diimplementasikan dan dijamin pelaksanaannya. Pada prinsipnya, dalam menghormati, melindungi dan menjamin HAM, konstitusi secara by design telah mengakui tiap-tiap individu yang memperjuangkan haknya, dalam hal ini para pembela HAM, agar mendapatkan perlindungan dari negara, dalam hal ini 
Pemerintah. Khususnya dalam Pasal 28 C ayat (2) UUD NRI 1945 telah dinyatakan bahwa, "Setiap orang berhak untuk memajukan dirinya dalam memperjuangkan haknya secara kolektif untuk membangun masyarakat, bangsa dan negaranya". Ketentuan ini menunjukkan adanya jaminan dari negara untuk memberi kesempatan kepada setiap orang untuk memperjuangkan haknya, termasuk menjamin perlindungan dan pemajuan HAM dan sekaligus memberi perlindungan terhadap para pembela HAM.

Apalagi, kewajiban itu ditambah dengan kewajiban internasional setiap negara untuk menghormati, melindungi dan menjamin HAM yang tidak sematamata didasarkan pada kewajiban atas suatu peraturan perundangan, tapi juga didasarkan pada moralitas untuk menjunjung tinggi harkat dan martabat manusia. Kewajiban negara semacam ini sebenarnya merupakan kewajiban mendasar bagi setiap pelaku dalam hubungan internasional, baik dalam skala nasional maupun internasional.

Bagaimanapun, sebagaimana dinukilkan Todung Mulya Lubis, bahwa semua pihak mengakui bahwa penegakan hak asasi manusia telah mengalami kemajuan yang pesat setelah Orde Baru ditumbangkan. Kalau dulu HAM itu tak utuh sebagai 'constitutionally guaranteed rights', sekarang keseluruhan pasal 28 UUD NRI 1945 yang sudah diamendemen memberikan kita semua norma-norma hak asasi manusia yang lumayan lengkap, tidak kalah dengan apa yang tertulis di "Universal Declaration of Human Rights" (Todung Mulya Lubis, 2009). Karena itu, upaya meneguhkan konstitusionalisme Indonesia seharusnya merupakan suatu kesatuan utuh dalam menegakkan HAM, dan dalam hal ini termasuk dalam melindungi para pembela HAM.

\section{SIMPULAN}

Penghormatan, perlindungan dan jaminan terhadap HAM merupakan salah satu karakteristik dari negara hukum Pancasila. Tidak saja termaktub dalam sila kedua Pancasila, maupun pada alinea pertama bagian Pembukaan UUD NRI 1945, namun juga terdapat dalam pasal-pasal atau batang tubuh UUD NRI 1945. Pasca amandemen pada tahun 1999-2002, UUD NRI 1945 telah mengatur jauh lebih lengkap dibandingkan sebelum amandemen, di mana dari 5 pasal (hak atas pekerjaan dan penghidupan yang layak bagi kemanusiaan, kemerdekaan berserikat dan berkumpul serta mengeluarkan pikiran dengan lisan dan tulisan, jaminan kemerdekaan beragama dan berkepercayaan, serta hak atas pengajaran, hak atas akses sumberdaya alam) menjadi setidaknya 17 pasal (dengan 38 substansi hak-hak yang beragam) yang terkait dengan HAM.

Episentrum penegakan HAM salah satunya memuat ihwal bagaimana perlindungan terhadap para pembela HAM, yang pada gilirannya harus menjadi objek keseriusan negara, dalam hal ini pemerintah, guna mengimplementasikan konstitusi. Pengakuan terhadap eksistensi para pembela HAM tidak saja diatur melalui UUD NRI 1945 selaku konstitusi, tetapi juga dalam berbagai produk hukum internasional. Oleh karenanya, upaya melindungi para pembela HAM di Indonesia merupakan satu kesatuan utuh dalam menegakkan UUD NRI 1945 selaku negara yang menganut negara hukum Pancasila. 


\section{SARAN}

Adapun saran penulis dalam penelitian ini diantaranya:

1. Diperlukan upaya untuk merevisi Undang-Undang Nomor 39 Tahun 1999 tentang HAM guna memperkuat perlindungan bagi para Pembela HAM. Dari revisi tersebut, diperlukan sejumlah pasal-pasal yang memuat secara defenitif dan khusus yang dapat melindungi para pembela HAM dalam melakukan aktivitasnya.

2. Diperlukan adanya upaya penyuluhan hukum di kalangan mahasiswa maupun di kalangan komunitas pemuda guna mewujudkan penguatan pengetahuan hukum terhadap nilai-nilai HAM yang diatur di dalam UUD NRI 1945.

3. Diperlukan upaya memperkuat mekanisme kelembagaan yang secara khusus memantau dan melakukan advokasi terhadap aktivitas yang dilakukan oleh para pembela HAM di Indonesia. Hal ini dapat dilakukan misalnya dengan memperkuat peran Komnas HAM sebagai lembaga yang kompeten menangani pelanggaran HAM yang dihadapi oleh para pembela HAM ketika melakukan aktivitasnya.

\section{DAFTAR PUSTAKA}

Asshiddique, Jimly. (2006). Konstitusi dan Konstitusionalisme Indonesia. Jakarta: Sekretariat Jenderal dan Kepaniteraan MKRI.

Barus, Zulfadli. (2013). "Analisis Filosofis tentang Peta Konseptual Penelitian Hukum Normatif dan Penelitian Hukum Sosiologis", Dalam Jurnal Dinamika Hukum, Vol. 13, No. 2.

Fajar, Mukti dan Yulianto Achmad. (2010). Dualisme Penelitian Hukum Normatif dan Empiris. Yogyakarta: Pustaka Pelajar.

Falaakh, Mohammad Fajrul. (2011). "Pancasila dan Konstitusi dalam Hukum Nasional", Dalam Makalah pada Seminar Hukum dan Konstitusi yang diselenggarakan Mahkamah Konstitusi RI dan Pusat Studi Pancasila UGM, Yogyakarta, 30 September-1 Oktober.

Herlambang, Wiratraman P. (2007). "Hak-Hak Konstitusional Warga Negara Setelah Amandemen UUD 1945: Konsep, Pengaturan dan Dinamika Implementasi". Dalam Jurnal Hukum Panta Rei, Vol. 1, No. 1, Desember.

Hidayat, Arif. (2019). "Negara Hukum Berwatak Pancasila", Dalam Makalah pada Peningkatan Pemahaman Hak Konstitusional Warga Negara bagi Asosiasi Dosen Pancasila dan Kewarganegaraan \& Asosiasi Profesi Pendidikan Pancasila dan Kewarganegaraan Indonesia”, Bogor, 21 Agustus. 
Isra, Saldi. (2014). "Peran Mahkamah Konstitusi dalam Penguatan Hak Asasi Manusia di Indonesia", Dalam Jurnal Konstitusi, Volume 11, Nomor 3.

Lubis, Todung Mulya. (2002). "Jaminan Konstitusi atas Hak Asasi Manusia dan Kebebasan". Dalam Melanjutkan Dialog dalam Reformasi Konstitusi di Indonesia: Laporan Hasil Konferensi Oktober 2001. Jakarta: International IDEA.

Lubis, Todung Mulya. (2009). "Menegakkan Hak Asasi Manusia, Menggugat Diskriminasi". Dalam Jurnal Hukum dan Pembangunan Tahun ke-39, No. 1, Januari-Maret.

Lembaga Studi dan Advokasi Masyarakat. (2020, 23 April). Diakses pada 5 Desember 2020. https://elsam.or.id/menatap-tahun-tahun-penuhmarabahaya-laporan-situasi-pembela-ham-atas-lingkungan-tahun-2019/

Muladi. (1997). Hak Asasi Manusia, Politik dan Sistem Peradilan Pidana. Semarang : Badan Penerbit Undip.

Rahayu. (2010). "Urgensi Perlindungan Hukum bagi Pembela Hak Asasi Manusia (Human Right Deffender) di Indonesia", Dalam Jurnal MMH, Jilid 39, No. 2, Juni.

Rahmatullah, Indra. (2020). "Meneguhkan Kembali Indonesia sebagai Negara Hukum Pancasila". Dalam Buletin Hukum \& Keadilan ADALAH, Volume 4, Nomor 2. 